\section{Effect of attitude similarity-dissimilarity on the utilization of additional stimulus inputs} in judgments of interpersonal attraction*

\author{
ARTHUR G. MILLER \\ Miami University, Oxford, Ohio 45056
}

In the context of a study in social judgment, Ss were presented with eight stimulus persons, varying in attitude similarity (to $S$ ), physical attractiveness, and favorability as judged by others. Ss were asked to rate these persons on a measure of interpersonal attraction. It was hypothesized that attitude similarity would operate as an "open gate" in disposing the S to utilize the attractiveness and favorability information, whereas dissimilarity would reduce the impact of these cues. This hypothesis received fairly strong support. The Ss' agreement with traits attributed to the stimulus persons provided validity data for the attraction response, the form of the interaction effect again showing greater utilization of additional stimulus information under conditions of similar, as opposed to dissimilar, stimulus persons.

Byrne and his associates (Byrne, 1969; Clore \& Byrne, 1970), in numerous investigations, have shown a positive linear relationship between attitude similarity and interpersonal attraction. Their technique generally involves the "bogus stranger" paradigm, in which stimulus persons (either on paper, tape, or live) are "made" to be similar or dissimilar to the experimental $S$ on the basis of previously acquired attitude responses. In the context of an interpersonal judgment study, Ss are asked to rate the strangers on various dimensions, one of which constitutes the dependent variable of attraction. There is also evidence that the data of this research paradigm are generalizable to situations with more ecological validity (e.g., Byrne, Ervin, \& Lamberth, 1970). Although there is controversy regarding the theoretical basis for the similarity-attraction effect (e.g., Berscheid \& Walster, 1969 , pp. 69-91), the findings have been highly consistent.

The concern of this study is the effect of attitude similarity-dissimilarity in conjunction with other stimulus inputs on the judgment process. We ordinarily do not learn merely that another person is similar or dissimilar to us, but rather we acquire other kinds of information about this target individual as well, e.g., the person's sex, physical appearance, social manner, etc. In view of the potency of the similarity variable as documented in previous research, however, one might expect that it would have a

*The writer wishes to thank Harry Brown, Robert Cohen, and Larry McFeeters for their assistance. Thanks are due also to David Probert of the Miami University Computing Center and to Dr. Leonard Giambra for his valuable comments. directing influence upon the perceiver's utilization of other stimulus information. It was hypothesized that attitude similarity-dissimilarity would operate as a gating mechanism in judgments of interpersonal attraction. Specifically, person's being similar, there should exist in the perceiver a more open posture with respect to additional stimulus inputs than under conditions of a stimulus person's being dissimilar. Knowing that another person is similar to us in attitudes should make us disposed toward discerning other features in terms of his attractiveness to us. If such a person is dissimilar, however, the perceptual gate closes and we are then not as likely to manifest the same concern or interest in attributes other than dissimilarity. This proposition was tested in the present study.

SUBJECTS

were 56 students from introductory psychology classes at Miami University (32 females, 24 males).

\section{PROCEDURE}

\section{General Overview}

The Ss were seen in two sessions. In the first, a group session, Ss were administered questionnaire booklets containing the attitude items used later to establish similarity or dissimilarity with a bogus stranger, in addition to several personality scales. ${ }^{1}$ Ss were next seen individually, approximately 2 weeks later. Each $S$ received eight folders and was asked to make various judgments about the person in each folder.

\section{Stimulus Dimensions}

In addition to attitude similarity-dissimilarity, it was decided to use the variables of physical attractiveness and others' opinions of under conditions of a stimulus the stimulus person. Attitude similarity-dissimilarity was manipulated by having the bogus stranger respond as the $\mathrm{S}$ responded on 10 of 12 (similar) or 2 of 12 (dissimilar) attitude items, ranging in content from the Vietnam war to college grades and the legitimacy of marihuana. The item format was agree-disagree. Physical attractiveness was manipulated by using college yearbook photographs of seniors, these having been scaled as to physical attractiveness in a previous study (Miller, 1970). Two levels (high, low) of photograph attractiveness were used. Others' opinions were manipulated by presenting to each $\mathbf{S}$ the views of three other (alleged) judges who were described as having seen the stimulus person's photograph and having read the attitude responses. Each judge "provided" five trait adjectives. For each stimulus person, the traits were either high $(M=24)$ or low $(M=13)$ in mean favorability, as composed from Anderson's listing (1968). ${ }^{2}$

\section{Experimental Design}

The various combinations of three stimulus dimensions, each at two levels, yielded a total of eight stimulus persons. The experimental design was a $2^{3}$ factorial, with repeated measures on each factor. Each $S$ thus judged eight stimulus persons. ${ }^{3}$ Each of eight photographs was paired equally often with similar and dissimilar stimulus persons and with favorable and unfavorable traits. ${ }^{4}$ However, each page of traits was always paired with the same combination of similarity-dissimilarity and attractiveness level. Each stimulus person was presented in a separate manila folder containing, on the left, the person's (alleged) photograph and attitude responses and, on the right, a typed listing of 15 trait adjectives (5 for each of three judges).

One ordering of the eight folders was set as: (1) similar, attractive, positive; (2) similar, attractive, negative; (3) similar, nonattractive, positive; (4) similar, nonattractive, negative; (5) dissimilar, attractive, positive; (6) dissimilar, attractive, negative; (7) dissimilar, nonattractive, positive; (8) dissimilar, nonattractive, negative. Each $\mathrm{S}$ judged eight folders, the order being controlled so that each folder appeared equally often in each of the eight positions.

Sex Variable

To incorporate the factors of sex of $S$ and stimulus person, four simultaneous, independent replications of this experiment were performed. The following headings will be used and referred to subsequently: Experiment 1-male Ss judging female stimulus persons; Experiment 2-male 
Table 1

Summary of Analysis of Variance of Attraction Ratings

\begin{tabular}{|c|c|c|c|c|}
\hline \multirow{3}{*}{ Source } & \multicolumn{4}{|c|}{ Experiment } \\
\hline & $\mathbf{1}^{\mathbf{a}}$ & $2^{b}$ & $3^{c}$ & $4^{d}$ \\
\hline & $\mathbf{F}$ & $\mathbf{F}$ & $\mathbf{F}$ & $\mathbf{F}$ \\
\hline A (Attitude Similarity) & $22.16 t$ & $10.12^{*}$ & $53.21 t$ & $46.61 \dagger$ \\
\hline B (Physical Attractiveness) & $13.08+$ & $\mathbf{3 . 8 4}$ & $25.12 t$ & $24.79 t$ \\
\hline C (Trait Favorability) & - & - & $13.01 t$ & $16.11+$ \\
\hline A by $B$ & 2.60 & $14.58 t$ & $5.07 *$ & $13.44 \dagger$ \\
\hline A by C & $6.21 *$ & $10.04 *$ & $4.89^{*}$ & - \\
\hline B by C & - & - & $13.49 t$ & - \\
\hline$A$ by $B$ by $C$ & 一 & - & - & - \\
\hline
\end{tabular}

$* p<.05, t p<.01$

a Male Ss-female stimuli $(d f=1 / 15)$, bmale Ss-male stimuli $(d f=1 / 7)$

cFemale $S$-female stimuli $(d f=1 / 15)$, demale $S_{s}$ male stimuli $(d f=1 / 15)$
Ss judging male stimulus persons; Experiment 3-female $S_{6}$ judging female stimulus persons; Experiment 4-female Ss judging male stimulus persons. A separate male $\mathrm{E}$ ran each experiment. 5

\section{Instructions to Ss} the importance of this kind of research, the Ss read the following: "We will present you with a number of each case you are provided with three kinds of data: (1) the person's photograph, (2) how that person filled out an attitude scale, and (3) how three other persons judged the stimulus person on the basis of his picture and attitudes. These data correspond to what psychologists generally feel are major sources of information about persons: What he or she looks like, what he or she believes, and how others respond to that individual. Please examine the materials in each folder carefully. Then fill out the social judgment scales that are provided in this booklet. The research supervisor will assist you and provide further materials."

\section{DEPENDENT VARIABLES}

\section{Attraction}

The primary dependent variable was obtained on the measure of attraction that has been used extensively by Byrne and his associates, the Interpersonal Judgment Scale. The last two items on this scale-personal feelings and working together in an experiment-are summed to yield an attraction score that can range from 2 to 14. Other items, each on a 7-point scale, ask for ratings on the stimulus person's morality, intelligence, knowledge of current events, and adjustment. After rating each stimulus person on this measure, Ss were asked to make several other judgments.

Agreement With Others' Traits

The traits representing others' opinions of the stimulus person constitute an attraction response-in this case, $\mathbf{S}$ witnessing the attraction or lack thereof of three other persons for
After preliminary notes regarding cases, each in a separate folder. For the stimulus person. This configuration produces a test of Heider's balance principle (1958), wherein there are two Os (i.e., $S$ and the other judges), each with affective reactions to a common object (i.e., the stimulus person). Of course, here it is assumed that $\mathbf{S}$ will have a like or dislike reaction to the stimulus person, depending upon his being similar or dissimilar to the stimulus person, respectively. All Ss were asked how much they agreed or disagreed with the other judges' trait descriptions of the stimulus persons. By summing over the three judges per stimulus person, each $S$ received eight agreement scores (ranging from 3-disagree-to 21-agree), one with respect to each stimulus person. It was expected that Ss would agree with judges who offered positive traits for similar strangers and negative traits for dissimilar strangers; Ss should disagree with judges who were favorable toward dissimilar strangers and unfavorable toward similar strangers.

\section{INDEPENDENT}

VARIABLE CHECKS

The Ss were asked to rate each stimulus person on how similar or dissimilar his attitudes were to those of $S$ himself, as to his (her) degree of physical attractiveness, and how favorable or unfavorable were the traits attributed to that person by the three judges.
SUBJECTS' REACTION TO STIMULUS INPUTS

After all previous ratings were collected, Ss were asked to rank, in order of usefuiness or importance, the photograph, the attitude responses, and the judges' trait descriptions (1-most important, 3-least important). The purpose of this procedure was to gather evidence regarding the Ss' perception of the relative importance of the stimulus inputs used in this research and to stimulus person would have an effect on the rank ordering.

\section{POSTEXPERIMENTAL} QUESTIONNAIRE

To preserve the integrity of the manipulations, Ss were not debriefed immediately after their participation. Questionnaires were mailed to each S after their participation under the guise of a general departmental survey. An open-ended question asking for S's reactions to "anything about this experiment that bothered you, or made you anxious, suspicious, or upset" was the critical item. Other questions concerned the E's courteousness, the clarity of instructions, and the S's interest in the experiment. The questionnaires were coded so as to identify the $S$ for potential purposes of relating the questionnaire and experimental responses. An announcement was then made concerning when and where $S$ could receive full information regarding the outcome of this study.

\section{RESULTS}

Postexperimental Questionnaire

Eighty-seven percent of the questionnaires were returned. Three Ss expressed suspicion that the trait adjectives might have been "rigged." Their data was not excluded from the analysis. No $S$ expressed suspicion regarding the manipulation of similarity-dissimilarity or that the photograph and attitudes were, in fact, unrelated. Several Ss expressed the conviction that making judgments on the basis of such limited information is unjust. Although questionnaires of this determine whether the sex of the $S$ or

Table 2

Mean Attraction Ratings Under Conditions of Attitude Similarity (Low, High), Physical Attractiveness, and Trait Favorability

Attitude Similarity and Physical Attractiveness at Two Levels of Trait Favorability

\begin{tabular}{|c|c|c|c|c|c|c|c|c|}
\hline \multirow{3}{*}{$\begin{array}{l}\text { Experi- } \\
\text { ment }\end{array}$} & \multicolumn{4}{|c|}{ Low } & \multicolumn{4}{|c|}{ High } \\
\hline & \multicolumn{2}{|c|}{ Attractive } & \multicolumn{2}{|c|}{ Nonattractive } & \multicolumn{2}{|c|}{ Attractive } & \multicolumn{2}{|c|}{ Nonattractive } \\
\hline & Positive & Negative & Positive & Negative & Positive & Negative & Positive & Negative \\
\hline $\begin{array}{l}1 \\
2 \\
3 \\
4\end{array}$ & $\begin{array}{l}7.06 \\
5.87 \\
7.56 \\
7.87\end{array}$ & $\begin{array}{l}8.31 \\
6.00 \\
7.81 \\
6.06\end{array}$ & $\begin{array}{l}6.17 \\
5.62 \\
7.75 \\
7.00\end{array}$ & $\begin{array}{l}6.81 \\
6.00 \\
5.75 \\
4.87\end{array}$ & $\begin{array}{l}11.06 \\
10.25 \\
12.25 \\
11.56\end{array}$ & $\begin{array}{r}9.87 \\
8.75 \\
10.94 \\
9.69\end{array}$ & $\begin{array}{r}8.81 \\
7.87 \\
10.87 \\
8.69\end{array}$ & $\begin{array}{l}8.00 \\
5.75 \\
8.31 \\
6.50\end{array}$ \\
\hline
\end{tabular}



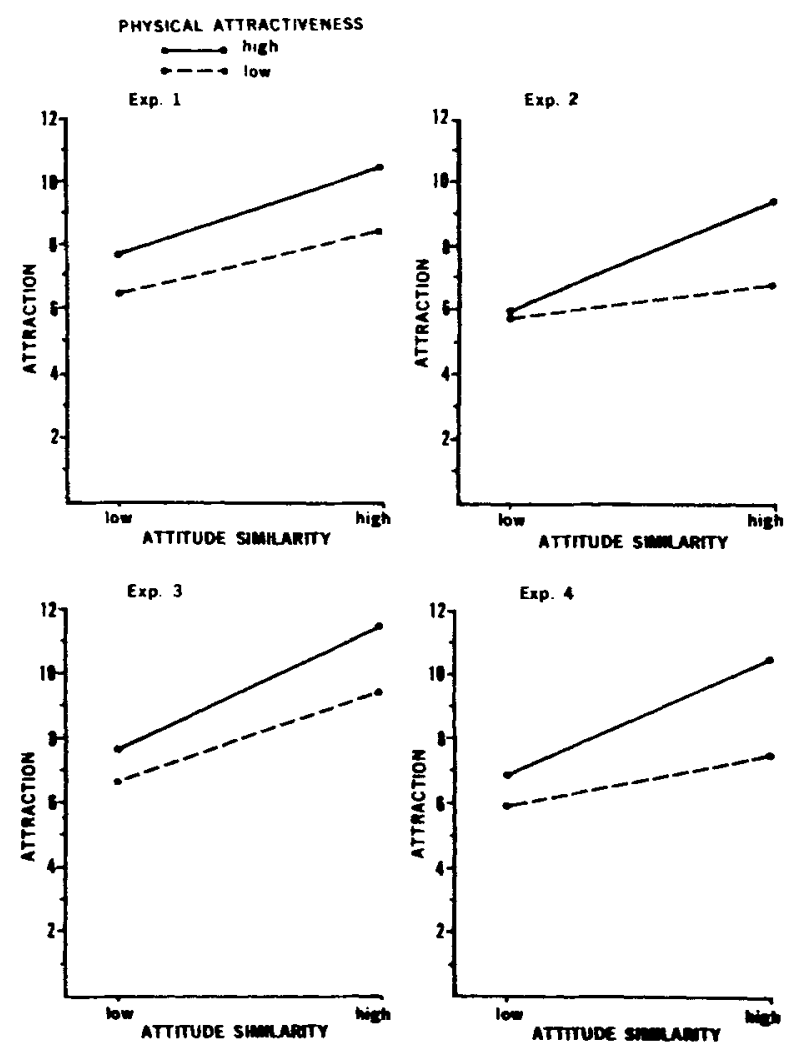

Fig. 1. Mean attraction ratings at two levels of attitude similarity and two levels of physical attractiveness.

kind have limitations in terms of validity (e.g., Levy, 1967), the evidence points to a low incidence of potentially disruptive suspiciousness.

Independent Variable Manipulations

Ratings of similarity-dissimilarity (1-dis, 21-sim), physical attractiveness (1-low, 21-high), and trait favorability (1-neg, 10-pos) were submitted to analysis of variance (Winer, 1962, p. 291). ${ }^{6}$ Main effects in the proper direction were achieved at high levels of significance $(p<.01)$ for each variable under the four experimental variations.

Interpersonal Attraction

The attraction scores for each stimulus person were submitted to analysis of variance. The summary of this analysis is shown in Table 1 , and the associated cell means are presented in Table 2.

The attitude similarity-dissimilarity effect is significant in each experiment, once again documenting the pervasiveness of Byrne's "law of attraction" (Byrne \& Nelson, 1965). Physical attractiveness appears as a significant main effect in three cases and as a trend in the expected direction in the fourth (Experiment 2 , $F=3.84, \quad$ df $=1 / 7, \quad \mathrm{p}<.10$ ). The effect for trait favorability attains significance in two cases, both involving female Ss (Experiments 3
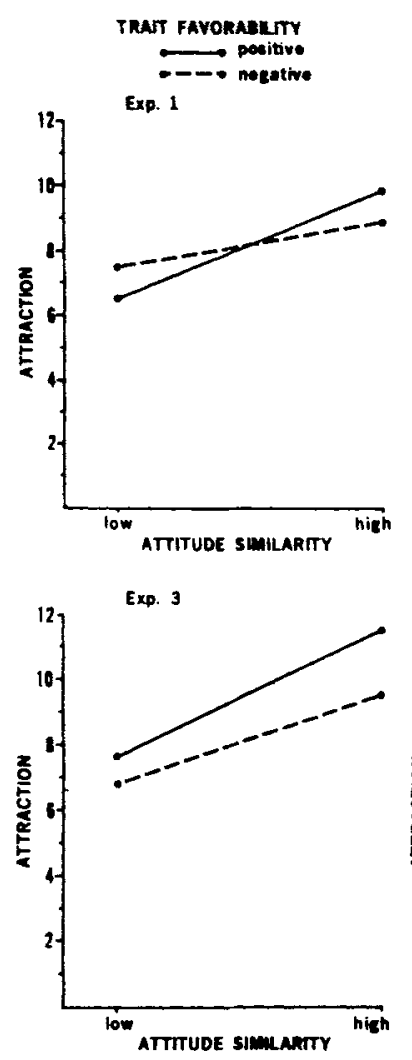

and 4) and fails to achieve significance in the cases involving male $S s$ (Experiments 1 and 2). Although admittedly post hoc, this pattern of results confirms numerous previous results documenting a more yielding or conforming social-judgment disposition in females than in males (e.g., Freedman, Carlsmith, \& Sears, 1970, p. 289). In view of the evidence cited regarding the effectiveness of the independent variable manipulations, it would appear that male Ss clearly recognize the differential favorability of the traits as here utilized, but are not (in terms of an overall main effect) disposed to making such cues a vital determinant of their attraction ratings.

Interaction effects involving attitude similarity and physical attractiveness attain significance in all but one case (Experiment 1). Cell means are displayed in Fig. 1.7 The interaction between attitude similarity and trait favorability also achieves significance in all but one case (Experiment 4). Cell means are displayed in Fig. 2. 8

The interaction effects, in general, occur as predicted. Under conditions of attitude similarity, the effects of the stimulus person's physical attractiveness (Experiments 2, 3, and 4) and attributed trait favorability (Experiments 1, 2, and 3) are more pronounced-and in the logical
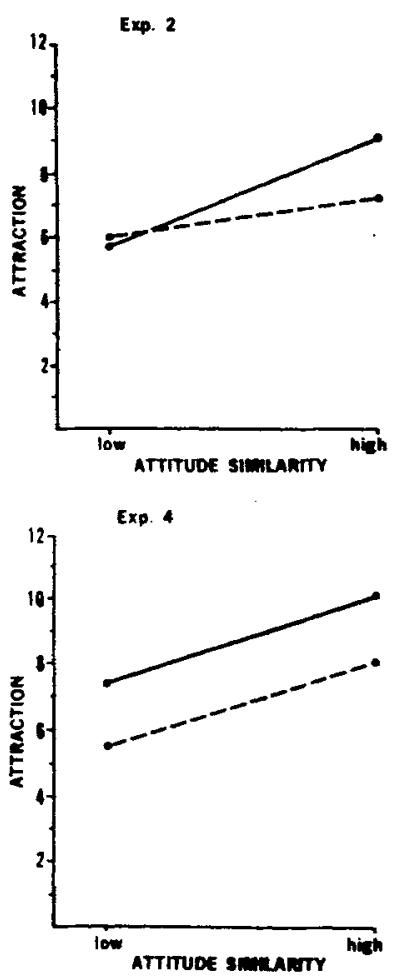

Fig. 2. Mean attraction ratings at two levels of attitude similarity and two levels of trait favorability. 
direction-than under conditions of attitude dissimilarity.

AGREEMENT WITH OTHERS' TRAIT DESCRIPTIONS

Agreement scores were submitted to analysis of variance. The Attitude Similarity by Trait Favorability interaction achieves significance $(p<.01)$ in each of the four experiments. Means for this interaction are displayed in Fig. $3 .^{9}$ The results provide a clear balance theory portrait: Ss agree with judges who are positive in describing similar strangers and negative toward dissimilar strangers; Ss disagree with judges who are negative toward similar strangers and positive toward dissimilar strangers. There is also the suggestion that with agreement scores-as in the case of attraction-others' opinions (i.e., traits) are more influential when the stimulus person is attitudinally similar rather than dissimilar to $S$.

SUBJECTS' RANKING OF STIMULUS INPUTS

Of the 56 total Ss, 49 (87\%) ranked attitude responses as the most important of the three stimulus dimensions. From one perspective, this figure reflects the operation of a dictum such as "beliefs are more important than looks or popularity." Given the relatively strong effects of physical attractiveness and trait favorability, however, it is also possible that an element of social desirability is involved-that $S$ s view attitudes to be the most appropriate dimension to rank first. There was considerably more variation in the Ss' assignments of second and third rankings. The mean rankings were as follows: attitude responses, 1.15 ; photograph, 2.19; others' traits, 2.29. No variation in stimulus ranking of interest in terms of sex. of $S$ or stimulus person were observed.

\section{DISCUSSION}

The primary hypothesis of this study receives fairly strong support. Attitude similarity-dissimilarity appears to operate as a "gate keeper" with respect to the utilization of additional stimulus information in judgments of attraction. It should be noted that the hypothesized interactions did not occur in ratings of other attributes of the stimulus person on the Interpersonal Judgment Scale (i.e., intelligence, knowledge of current events, morality, adjustment). Hence the effect may be unique to judgments of an interpersonal nature. One might ask whether the similarity-dissimilarity of a stimulus person operates more on the perception of additional stimulus information or on the Ss' disposition to utilize such information. As a preliminary answer to this question, it
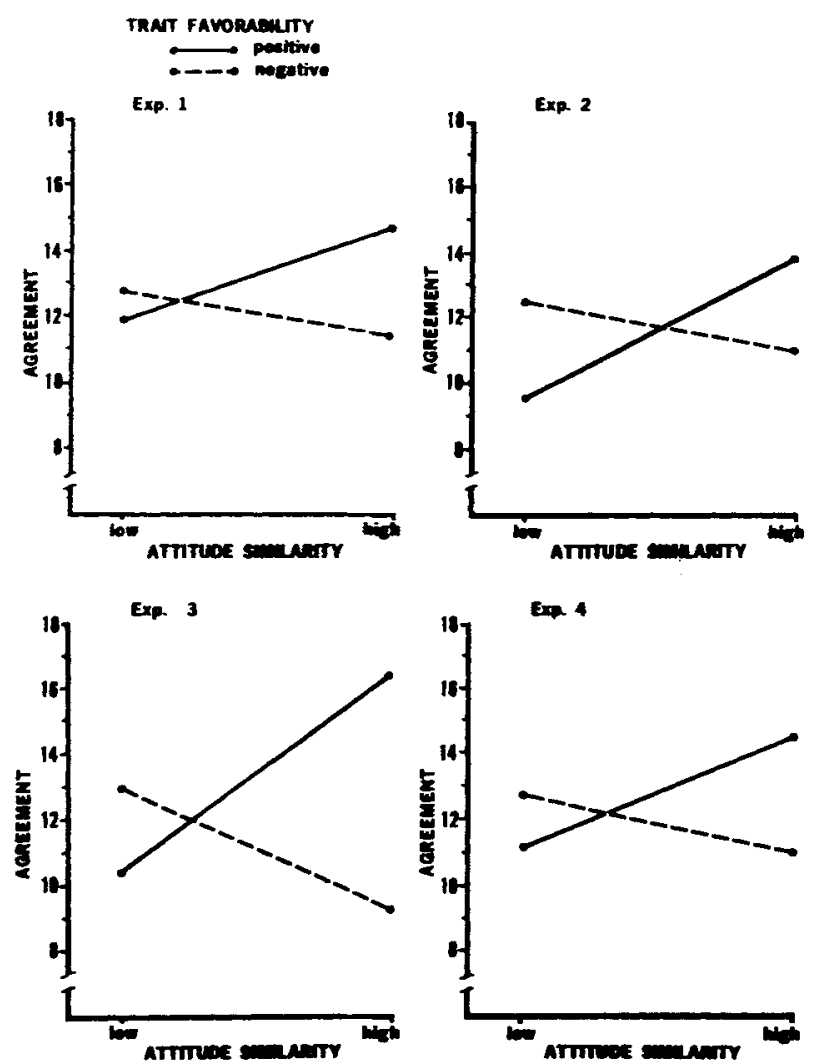

Fig. 3. Mean agreement scores at two levels of attitude similarity and two levels of trait favorability.

is relevant to point out that in the analysis of variance for checks on the independent variables (physical attractiveness and trait favorability) there were no significant interactions with attitude similarity. This suggests that Ss were able to recognize differences in attractiveness or favorability in dissimilar as well as in similar stimulus persons. Hence, the obtained interactions in the case of the attraction measure reflect differences in the disposition to utilize information that is available, not differences in the social perception of dissimilar and similar stimulus persons. These results, although encouraging, should not be overinterpreted. They may be limited to the particular levels of the variables used in this research, and there are two instances in which the predicted interaction does not occur. Methodologically, it remains to be seen whether these results will appear in a transition from photographic stimuli to "live" strangers.

The agreement data serve as an alternate and perhaps less obtrusive measure of attraction, thus constituting validity data for the attraction response as measured in Byrne's paradigm. The form of the obtained interactions regarding the agreement response, shown in Fig. 3, are quite in line with the hypothesized interaction effects for attraction scores. This may be regarded as tentative evidence for the reliability or generality of the primary hypothesis of this research.

It must be noted that two previous studies have exposed Ss to combinations of similar and dissimilar strangers at two or more levels of physical attractiveness (Byrne, London, \& Reeves, 1968; Stroebe, Insko, Thompson, \& Layton, 1971). Although main effects for these independent variables were obtained in both experiments-as in the present one-neither investigation produced the interaction effects reported in this paper. A major difference in experimental design may be involved, for both previous experiments utilized an independent-groups paradigm, in which Ss were asked to rate only one stimulus person. The present experiment used a repeated-measures design in which Ss were exposed to various combinations of stimulus inputs. This suggests the intriguing possibility that social judgment processes operate differently in the context of single as opposed to multiple stimulus persons. This is an important problem for further study.

\section{REFERENCES}

ANDERSON, N. H. Likableness ratings of 
555 personality trait words. Joumal of Personality \& Social Psychology, 1968, 9 , 272-279.

BERSCHEID, E., \& WALSTER, E. H Interpersonal attraction. Reading, Mass: Addison-Wesley, 1969.

BYRNE, D. Attitudes and attraction. In $L$. Berkowitz (Ed.), Advances in experimental social psychology. Vol. 4. New Yodk: Academic Press, 1969.

BYRNE, D., ERVIN, C. R., \& LAMBERTH, J. Continuity between the experimental study of attraction and real-life computer dating. Journal of Personality \& Social Psychology, 1970, 16, 157-165.

BYRNE, D., LONDON, O., \& REEVES, $K$. The effects of physical at tractiveness, sex, and attitude similarity on interpersonal attraction. Joumal of Personality, 1968. 259-271.

BYRNE, D., \& NELSON, D. Attraction as a linear function of proportion of positive reinforcements. Journal of Personality \& Social Psychology, 1965, 1, 659-663.

CLORE, G. L., \& BYRNE, D. The process of personality interaction. In R. B. Cattell (Ed.), Handbook of modern personality theory. Chicago: Aldine, 1970.

FREEDMAN, J. L., CARLSMITH, J. M., \& SEARS, D. O. Social psychology. Englewood Cliffs, N.J: Prentice-Hall, 1970.

HEIDER, F. The psychology of interpersonal relations. New York: Wiley, 1958.

LEVY, L. H. Awareness, learning, and the beneficent subject as expert witness. Journal of Personality \& Social Psychology, 1967, 6, 365-370.

MILLER, A. G. Role of physical attractiveness in impression formation. Psychonomic Science, 1970. 19. 241-243. STROEBE, W., INSKO, C. A., THOMPSON. V. D., \& LAYTON, B. D. Effects of physical attractiveness, attitude similarity, and sex on various aspects of interpersonal attraction. Journal of Personality \& Social Psychology, 1971. 18, 79-91.

WINER, B. J. Statistical principles in experimental design. New York: McGraw-Hill, 1962.

\section{NOTES}

1. The scales administered were the Marlowe-Crowne social desirability scale and Rotter's internal-external control scale, in addition to several attitude items dealin with political figurs and current events. These were to serve as buffers to avoid sensitizing $S s$ to the items used later in establishing similarity or dissimilarity with the stimulus persons. Subsequent correlational analyses involving the two personality scales and $\mathbf{S} s^{\prime}$ social-judgment responses provided data of marginal significance and will not be reported.

2. Favorable adjectives ranged in likableness from 3.65 to 5.49 ; unfavorable traits ranged from 2.22 to 3.57 . An example of a set of favorable traits was the following: thoughtful, mature, well-spoken, trusting, systematic; wise, reliable, subtle, educated, likable; considerate. good-natured, sensitive, reasonable, companionable. An unfavorable set was the following: dependent, moralistic, forgetful, inhibited, opportunistic; unsystematic, talkative, uninquisitive, crafty, theatrical; unskilled, self-conscious, unsophisticated, withdrawing, irreligious.

3. Each $S$ judged four similar and four dissimilar strangers. The proportions of $10 / 12$ (similar) and $2 / 12$ (dissimilar) were maintained, although the specific items upon which $S$ agreed or disagreed with the stimulus persons were systematically varied.

4. By making duplicates of the photographs, the same stimulus persons were used in Experiments 1 and 3 (female) and Experiments 2 and 4 (male).

5. In Experiments 1,3 , and $4, N=16$; in Experiment 2, $N=8$.

6. The ANOVAs reported in this paper are based on an $\mathrm{N}$ by 2 by 2 by 2 factorial experiment. $N$ represents a $S$ factor, and the remaining factors are attitude similarity, physical attractiveness, and trait favorability-each at two levels. In each case, the denominator for an $F$ ratio is the corresponding interaction with the $S$ factor.

7. Cell comparisons are analyzed by $t$ tests for paired observations. Differences between means under low attitude similarity are significant at the .05 level in Experiments 3 and 4 ; under $h i g h$ similarity they are significant at the .01 level in each experiment.

8. Differences between means under low similarity are significant at the .05 level in Experiment 3 and at the .01 level in Experiment 4; under high similarity, they are significant at the .01 level in Experiments 3 and 4.

9. Differences between means under low similarity are significant at the 05 level in Experiments 2 and 3 ; under high similarity, they are significant at the .01 level in each experiment. 